having fits, small delays in controlling the fits can lead to a worse outcome for both the mother and the fetus.

Duley advises that doctors should be taught how to use magnesium. We agree, but the fact remains that most junior obstetricians will rarely be required to treat a patient with eclamptic fits. With the introduction of structured training, some trainees will receive their certificate of specialist training without managing a single case. In contrast, most doctors learn how to control noneclamptic fits with diazepam during the preregistration year. It seems logical that this experience will enable trainee obstetricians to use diazepam safely and confidently in emergencies. Despite being experienced obstetricians who are familiar with magnesium, we have to review the protocol before using it. This is not the case for diazepam, which comes in a formulation that is ready to use. Interestingly, one of the women in Crowther's study who was allocated to receive magnesium died of a cardiac arrest immediately after the infusion, "presumably as a result of too rapid an injection." ${ }^{3}$ Furthermore, examination of the two reports that Duley cites in support of magnesium to prevent recurrent fits shows that immediate control of active eclampsia was not their focus. ${ }^{3}{ }^{4}$

Diazepam is effective at arresting convulsions, ${ }^{3}$ the excess of recurrent fits with diazepam occurs after the first hour, ${ }^{3}$ and maternal morbidity is otherwise the same for diazepam and magnesium. ${ }^{4}$ We conclude that diazepam is good drug for the immediate control of eclampsia and that magnesium is better to prevent recurrent fits.

ROBERT FOX

Taunton and Somerset Hospital,

Consultant Taunton TA1 5DA

TIM DRAYCOTT Obstetric registra

Gloucester Royal Infirmary,

Gloucester GL1 3NN

Duley L. Magnesium sulphate should be used for eclamptic fits. $B M F$ 1996;312:639. (9 March.)

2 Fox R, Draycott T. Prefer diazepam for initial control of pre-eclamptic fits. BMF 1995;311:1433. (25 November)

3 Crowther C. Magnesium sulphate versus diazepam in the management of eclampsia: a randomised controlled trial. $B r$ management of eclampsia: a rand.

4 Eclampsia Trial Collaborative Group. Which anticonvulsan for eclampsia? Evidence from the collaborative eclampsia trial. Lancet 1995;345:1455-63.

\section{Screening for diabetic retinopathy}

\section{Diabetic patients should continue to be assessed by direct ophthalmoscopy}

EDITOR,-There has been much discussion in the $B M F$ recently about the merits and shortcomings of various modes of screening for diabetic retinopathy. ${ }^{1-3}$ Many diabetologists and general practitioners are now confused about the value of regular direct ophthalmoscopy for their diabetic patients because of its perceived poor sensitivity.

This is of great concern, and we think that a clearer distinction must be made between screening for any retinopathy and screening for sight threatening retinopathy (that is, proliferative retinopathy or macular oedema). Although J P O'Hare and colleagues allude to the problem and give figures for both, ${ }^{3}$ most published figures for sensitivity and specificity refer to screening for sight threatening retinopathy. ${ }^{12}$ While it is true that no treatment is necessary for retinopathy that is not sight threatening and purists might argue that screening for a condition that does not have an effective treatment is not justified, the efficacy of laser photocoagulation for sight threatening retinopathy depends on both accurate and timely diagnosis of this treatable subset of the condition. However, little if any research has been carried out on the best means of following up patients who are known to have retinopathy that is not yet sight threatening. With regard to maculopathy, the detection of retinal thickening close to the fovea requires considerable skill, and measuring visual acuity has been shown to have no significant beneficial effect on sensitivity while lowering specificity. ${ }^{2}$

Therefore, since there is no perfect way of screening for sight threatening retinopathy and since, at any time, about $70 \%$ of the diabetic population does not have retinopathy, we suggest that all patients with appreciable retinopathy (defined as more than six to eight microaneurysms, or any haemorrhage or exudate or cottonwool spots, or any new vessels) should be referred for a thorough assessment by an ophthalmologist. This will allow follow up visits to be scheduled on the basis of known prognostic indicators. ${ }^{4}$

Laser photocoagulation is much better at preserving visual function than at restoring loss. If the progression of the microvasculopathy is monitored by someone who is experienced in treating sight threatening retinopathy the decision of when to treat is within that person's control and the optimal time is more likely to be identified.

Organised community screening programmes for diabetic retinopathy (at whatever stage) are not yet available nationwide. Until they are, doctors caring for diabetic patients should continue to perform direct ophthalmoscopy through dilated pupils to detect any signs of this frequently asymptomatic cause of visual morbidity.

P M HART

Consultant community ophthalmologist D B ARCHER Professor

Department of Ophthalmology Royal Victoria Hospital,

Belfast BT12 6BA

Sir George E Clark Metabolic Unit,

A B ATKINSON

Royal Victoria Hospital

Beyal Victoria HT12 6BA

1 Ryder B. Screening for diabetic retinopathy. $B M$ 1995;311:207-8. (22 July.)

2 Harding SP, Broadbent DM, Neoh C, White MC, Vora J. Sensitivity and specificity of photography and direct ophthalmoscopy in screening for sight threatening eye disease: the Liverpool diabetic eye study. BMf 1995;311:1131-5. (28 October.)

3 O'Hare JP, Hopper A, Madhaven C, Charney M, Purewal TS, Harney B, Griffiths J. Adding retinal photography to screening for diabetic retinopathy: a prospective study in primary care. $B M F$ 1996;312:679-82. (16 March.)

4 Klein BEK, Davis MD, Segal P, Long JA. Diabetic retinopathy. Assessment of severity and progression. Ophthalmology 1984;91:10-7.

\section{True costs are different from those given in} paper

EDITOR,-I believe that there are problems with the costing used in J P O'Hare and colleagues' study of the effect of adding retinal photography to screening for diabetic retinopathy.

Firstly, no detail of the method is given. The figure of $£ 12.50$ for the cost of adding photography first appears in the discussion, and it would be useful to know what it includes (for example, labour, materials, capital for camera and van).

Secondly, the cost per patient whose sight is saved is based on dividing the extra cost of adding photography to the screening of 3500 patients (at $£ 12.50$ per patient this is $£ 43750$ ) by the total number of patients whose sight is saved (this being regarded as equivalent to the number given laser treatment). Table 1 , however, shows that the sensitivity of referral is increased by only $8 \%$ by adding photography ( $65 \%$ to
$73 \%$ ) or by $19 \%$ by adding photographs reviewed by a specialist ( $65 \%$ to $84 \%)$. The extra cost of photography should be divided only by the number of extra patients whose sight is saved by the extra referrals. If 100-125 patients need referral, only 8-10 would be added by photography; if the proportion requiring laser treatment is similar $(50 \%$ or $40 \%$, based on 50 from 100 or 125) then the number of extra patients whose sight was saved would be about four (three to five, ranging from $40 \%$ of 8 to $50 \%$ of 10 ). This is because the general practitioners and optometrists (combined) were already referring most of the patients who needed referral. When the marginal cost of $£ 43750$ is divided by the marginal number of patients whose sight was saved (four) the true cost of adding photography is shown to be $£ 10937.50$ per patient whose sight is saved. The paper's "key message" box is therefore misleading.

It would have been more useful to consider separately the cost per referral for each screening method (general practitioner, optometrist, and photography) and to turn the question roundthat is, to ask what screening by a general practitioner or optometrist adds to screening by photography with a specialist reporting on the photographs. Only screening by an optician is competitive $(75 \% v 75 \%)$, and the choice then depends on a comparison of costs. Adding photography to examination by an optician improves sensitivity by $13 \%$ ( $75 \%$ to $88 \%$ ), and that requires marginal analysis with the costs being based on the optician taking the photographs; there will be a reduced capital cost (camera only) and reduced labour cost, especially since diabetic patients are entitled to free annual eye checks. The NHS therefore already incurs most of the cost of screening by an optician, and the marginal cost of photography would be low.

N R WAUGH Director

Scottish Health Purchasing Information Centre,

Summerfield House,

Aberdeen AB9 1RE

1 O'Hare JP, Hopper A, Madhaven C, Charny M, Purewal TS, Harney B, et al. Adding retinal photography to screening for diabetic retinopathy: a prospective study in primary care. BMF 1996;312:679-82. (16 March.)

\section{Authors' reply}

EDITOR,-P M Hart and colleagues' statement that doctors caring for diabetic patients should continue to perform direct ophthalmoscopy is a message that needs to be supported. Our paper provides evidence that, in an organised community screening programme, combining ophthalmoscopy and retinal photography improves performance, and our experience is that it enhances the skills of the doctors undertaking ophthalmoscopy and their referral at the most appropriate stage to the ophthalmologist.

N R Waugh raises interesting points about marginal costs for photography. The figure of $£ 12.50$ for the screening service includes the photographer's and clinical specialist's salaries, film costs, camera and vehicle maintenance, and a depreciation element for the capital replacement of camera and van. The cost per patient whose sight was saved was calculated by use of combined modalities in an organised screening service on the assumption that the total package was necessary to achieve a sufficiently high sensitivity. Clearly if only the additional value of one modality (whether ophthalmoscopy or fundal photography) is assessed the marginal costs for the other seem high. A fuller analysis of costs for the different modalities has been made in previous studies, ${ }^{1}$ and our paper did not attempt to repeat this. 